\title{
Differences in Morphologic and Hemodynamic Characteristics for "PHASES-Based" Intracranial Aneurysm Locations
}

\author{
(D) N. Varble, (DH. Rajabzadeh-Oghaz, (D). Wang, (D) A. Siddiqui, (DH. Meng, and (D) A. Mowla
}

\begin{abstract}
BACKGROUND AND PURPOSE: Several recent prospective studies have found that unruptured intracranial aneurysms at various anatomic locations have different propensities for future rupture. This study aims to uncover the lack of understanding regarding ruptureprone characteristics, such as morphology and hemodynamic factors, associated with different intracranial aneurysm location.
\end{abstract}

MATERIALS AND METHODS: We investigated the characteristics of 311 unruptured aneurysms at our center. Based on the PHASES study, we separated and compared morphologic and hemodynamic characteristics among 3 aneurysm location groups: 1) internal carotid artery; 2) middle cerebral artery; and 3) anterior communicating, posterior communicating, and posterior circulation arteries.

RESULTS: A mixed model statistical analysis showed that size ratio, low wall shear stress area, and pressure loss coefficient were different between the intracranial aneurysm location groups. In addition, a pair-wise comparison showed that ICA aneurysms had lower size ratios, lower wall shear stress areas, and lower pressure loss coefficients compared with MCA aneurysms and compared with the group of anterior communicating, posterior communicating, and posterior circulation aneurysms. There were no statistical differences between MCA aneurysms and the group of anterior communicating, posterior communicating, and posterior circulation aneurysms for morphologic or hemodynamic characteristics.

CONCLUSIONS: ICA aneurysms may be subjected to less rupture-prone morphologic and hemodynamic characteristics compared with other locations, which could explain the decreased rupture propensity of intracranial aneurysms at this location.

ABBREVIATIONS: AcomA = anterior communicating artery; IA = intracranial aneurysm; LSA = low wall shear stress area; PcomA = posterior communicating artery; PHASES = Population, Hypertension, Age, Size of aneurysm, Earlier SAH from another aneurysm, and Site of aneurysm; PLc = pressure loss coefficient; $\mathrm{SR}=$ size ratio; WSS $=$ wall shear stress

$I^{\prime \prime m}$ tracranial aneurysms (IAs) occur in approximately $3 \%$ of the population. ${ }^{1}$ Although the rupture rate is very low, ${ }^{2}$ the consequences of rupture are devastating. With increased detection of incidental IAs, clinicians are routinely faced with the decision of whether to treat. However, because treatment carries substantial

\footnotetext{
Received February 21, 2017; accepted after revision June 9.

From the Department of Mechanical and Aerospace Engineering (N.V., H.R.-O., H.M.), Toshiba Stroke and Vascular Research Center (N.V., H.R.-O., A.S., H.M.), Departments of Biostatistics (J.W., A.M.), Neurosurgery (A.S., H.M.), Biomedical Engineering (H.M.), and Neurology (A.M.), University at Buffalo, State University of New York, Buffalo, New York.

This work was supported by National Institutes of Health grants (R01 NS091075 and R03 NS090193) and resources from the Center for Computational Research at the University at Buffalo.

Please address correspondence to Ashkan Mowla, MD, FAHA, FAAN, Department of Neurology, Gates Vascular Institute, School of Medicine and Biomedical Sciences, University at Buffalo, State University of New York, 100 High St, Buffalo, NY 14203; e-mail: mowla_a@yahoo.com

-- Indicates open access to non-subscribers at www.ajnr.org

http://dx.doi.org/10.3174/ajnr.A5341
}

risk, ${ }^{3}$ the decision is difficult at times. Therefore, objective guidelines are required to assess the aneurysm rupture risk.

Several prospective studies have found that aneurysm size and location may play a significant role in IA rupture propensity and, consequently, are among the most important factors that clinicians consider for IA management. ${ }^{2,4}$ In the landmark International Study of Unruptured Intracranial Aneurysms, ${ }^{4}$ the highest rupture rates at 5-year follow-ups occurred in aneurysms located in the posterior circulation. Later, the PHASES (Population, Hypertension, Age, Size of aneurysm, Earlier SAH from another aneurysm, and Site of aneurysm) study pooled the analyses of 6 prospective cohort studies and found that the patient's geographic region, hypertension status, age, IA size, history of SAH, and IA site were independent predictors of aneurysm rupture. ${ }^{4}$ More specifically, the PHASES study showed that aneurysms in the ICA location had the lowest risk of rupture; aneurysms in the MCA had a medium risk of rupture; and anterior communicating artery (AcomA), posterior communicating artery (PcomA), and posterior circulation artery aneurysms had the highest risk of rupture. ${ }^{4}$ 
Table 1: Description of the patient population

\begin{tabular}{|c|c|c|c|c|c|c|c|}
\hline & \multicolumn{2}{|c|}{ ICA } & \multirow[b]{2}{*}{ MCA } & \multicolumn{3}{|c|}{ AcomA/PcomA/Post } & \multirow[b]{2}{*}{ Total } \\
\hline & $\begin{array}{c}\text { ICA } \\
\text { Cavernous }\end{array}$ & ICA & & AcomA & PcomA & $\begin{array}{l}\text { Posterior } \\
\text { Circulation }\end{array}$ & \\
\hline Age (years $\pm S D$ ) & $58 \pm 12$ & $59 \pm 14$ & $60 \pm 10$ & $58 \pm 13$ & $64 \pm 11$ & $61 \pm 13$ & $59 \pm 13$ \\
\hline \multicolumn{8}{|l|}{ No. of patients } \\
\hline Hypertension & 21 & 40 & 18 & 23 & 11 & 25 & 138 \\
\hline Smoking & 22 & 44 & 10 & 25 & 6 & 17 & 124 \\
\hline Earlier SAH & 3 & 1 & 1 & 7 & 0 & 3 & 15 \\
\hline IA multiplicity & 10 & 41 & 6 & 3 & 1 & 4 & 65 \\
\hline Number of IAs & 51 & 111 & 41 & 46 & 15 & 47 & 311 \\
\hline $\begin{array}{l}\text { Total No. of patients (\% of } \\
\text { entire population) }\end{array}$ & $40(16 \%)$ & $86(34 \%)$ & $31(12 \%)$ & $37(15 \%)$ & $12(5 \%)$ & $45(18 \%)$ & 251 \\
\hline
\end{tabular}

\section{Morphologic Factors}

To generate 3D models for morphologic and hemodynamic calculations, angiographic images were segmented in the Vascular Modeling Toolkit (www.vmtk.org). ${ }^{8}$ 3D morphologic calculations were performed in a custom Matlab code (R2014a; MathWorks, Natick, Massachusetts). A detailed description of the calculated parameters can be found in previous literature. ${ }^{9,10}$ Briefly, aneurysm size is the maximum distance from the center of the neck plane to a point in the an-

Although it is generally accepted that aneurysms in different locations have a different risk of rupture and growth, there remains a lack of understanding regarding the geometric differences and the potentially different hemodynamic forces imposed on aneurysms at different locations. In this study, by using 3D morphologic calculations and hemodynamics parameters from image-based computational fluid dynamics, we investigated differences between IAs at different locations. We consecutively collected 311 unruptured aneurysms from our center and split them into 3 locations according to the perceived risk of rupture based on the PHASES score. ${ }^{4}$ The first group (PHASES risk score of 0 ) consisted of ICA and ICA cavernous aneurysms; the second group (PHASES risk score of 2) consisted of MCA aneurysms; and the third group (PHASES risk score of 4) consisted of AcomA, PcomA, and posterior circulation aneurysms. Using a mixed model analysis and pair-wise comparisons, we aimed to reveal if these aneurysm locations had different rupture-prone morphologic and hemodynamic characteristics.

\section{MATERIALS AND METHODS Population}

Three hundred eleven (311) saccular IAs from 251 patients were consecutively collected between 2006 and 2013 with institutional review board approval at the Buffalo General Hospital University at Buffalo (Buffalo, New York). This dataset was partially derived from a previously analyzed dataset of 119 IAs $^{5}$ and, later, 204 IAs. ${ }^{6,7}$ Patients who met the selection criteria underwent 3D imaging, had an unruptured IA at the time of imaging, and had sufficient image quality for 3D segmentation. A description of the comorbidities of the patients included in our cohort are summarized in Table 1.

The aneurysms were separated into 3 location-based categories based on the PHASES score. ${ }^{4}$ The first group consisted of aneurysms in the ICA. The second group consisted of MCA aneurysms. The third group consisted of AcomA, PcomA, and posterior circulation aneurysms and is termed the AcomA/PcomA/ Post aneurysm group. The IAs of the posterior circulation included the aneurysms from the basilar artery, basilar tip, posterior cerebral artery, cerebellar arteries, and intracranial vertebral artery. There were 162 ICA aneurysms (ICA cavernous, 51; other ICA, 111), 41 MCA aneurysms, and 108 AcomA/PcomA/Post aneurysms (AcomA, 46; PcomA, 15; posterior circulation, 47). eurysm dome, size ratio (SR) is the ratio of the IA size to the parent vessel diameter, aspect ratio is the ratio of the IA size to the neck diameter, undulation index is the degree of surface irregularity, ellipticity index is the deviation of the IA from a perfect hemisphere, and nonsphericity index is the deviation of the IA from a perfect hemisphere while also considering surface undulations.

\section{Computational Fluid Dynamics Methods}

To simulate blood flow and compute hemodynamic factors for all aneurysm geometries, pulsatile computational fluid dynamics simulations were conducted according to previously detailed methodology. ${ }^{5}$ Based on grid-refinement studies, computational meshes were generated consisting of 300,0001.5 million volumetric tetrahedral elements. To ensure proper resolution at the wall, 4 refined prism layers were generated with a maximum size equal to one-tenth of the volumetric element size. Meshes were generated by using ICEM CFD (ANSYS, Canonsburg, Pennsylvania). Computational fluid dynamics simulations were run in STAR-CCM+ (CD-adapco, Melville, New York). A rigid wall, no-slip boundary condition, and Newtonian fluid properties were assumed ( $\rho=1056 \mathrm{~kg}$ ) $\mathrm{m}^{3} ; \mu=3.5 \mathrm{cP}$ ). A pulsatile waveform was taken from a transcranial Doppler sonography measurement from a healthy patient and imposed at the vessel inlet, ${ }^{5}$ and the principle of minimum work, or flow split assumption, was applied at the outlet. ${ }^{11}$ A pressure implicit with splitting of operator algorithm was applied for temporal discretization, and a secondorder upwind-differencing scheme was used for spatial discretization to solve the transient incompressible Navier-Stokes equations. To assure numerically stable results, each pulsatile simulation was run for 3 cardiac cycles, and the last cycle was used for analysis. Postprocessing was performed in Tecplot 360 (Tecplot, Bellevue, Washington).

\section{Hemodynamic Factors}

The hemodynamic factors analyzed included: normalized time-averaged wall shear stress (WSS), or the average of the frictional or tangential force on the aneurysm wall normalized by parent artery time-averaged WSS; oscillatory shear index (OSI), or the average of the directional change of WSS over 1 cardiac cycle; relative residence time (RRT), or the average relative time that blood spends at the wall; low WSS area (LSA), 
Table 2: Statistical comparison of morphologic and hemodynamic factors between aneurysms from the 3 PHASES-based locations ${ }^{a}$

\begin{tabular}{lcccc}
\hline \multicolumn{1}{c}{ Factors } & $\begin{array}{c}\text { ICA } \\
\text { Mean } \pm \text { SD }\end{array}$ & $\begin{array}{c}\text { MCA } \\
\text { Mean } \pm \text { SD }\end{array}$ & $\begin{array}{c}\text { AcomA/PcomA/Post } \\
\text { Mean } \pm \text { SD }\end{array}$ & $\begin{array}{c}\text { Overall Comparison } \\
\text { P Value }\end{array}$ \\
\hline Size $(\mathrm{mm})$ & $5.11 \pm 3.72$ & $4.45 \pm 2.39$ & $4.74 \pm 3.61$ & .6236 \\
SR & $1.54 \pm 1.17$ & $2.35 \pm 1.25$ & $2.45 \pm 2.22$ & $<.0001^{\mathrm{b}}$ \\
AR & $1.11 \pm 0.58$ & $1.26 \pm 0.64$ & $1.18 \pm 0.71$ & .3916 \\
UI & $0.058 \pm 0.050$ & $0.074 \pm 0.057$ & $0.066 \pm 0.071$ & .1318 \\
EI & $0.119 \pm 0.058$ & $0.138 \pm 0.062$ & $0.132 \pm 0.058$ & .0719 \\
NSI & $0.142 \pm 0.069$ & $0.164 \pm 0.072$ & $0.152 \pm 0.064$ & .1679 \\
WSS & $0.66 \pm 0.36$ & $0.53 \pm 0.37$ & $0.57 \pm 0.52$ & .0121 \\
OSI & $0.005 \pm 0.008$ & $0.005 \pm 0.011$ & $0.011 \pm 0.049$ & .0413 \\
RRT & $2.38 \pm 2.97$ & $3.98 \pm 6.15$ & $4.09 \pm 5.40$ & .0050 \\
LSA & $0.097 \pm 0.182$ & $0.206 \pm 0.271$ & $0.198 \pm 0.271$ & $.0003^{\mathrm{b}}$ \\
MWSS & $4.43 \pm 2.12$ & $4.49 \pm 5.06$ & $3.98 \pm 2.53$ & .0358 \\
PLC & $2.64 \pm 3.71$ & $6.06 \pm 5.23$ & $5.88 \pm 5.71$ & $<.0001^{\mathrm{b}}$ \\
EL $\left(\mathrm{W} / \mathrm{m}^{3}\right)$ & $6193 \pm 11339$ & $6505 \pm 8593$ & $7793 \pm 12539$ & .5271
\end{tabular}

Note:-AR indicates aspect ratio; El, ellipticity index; EL, energy loss; MWSS, maximum normalized wall shear stress; NSI, nonsphericity index; OSI, oscillatory shear index; Post, posterior circulation; RRT, relative residence time; UI, undulation index.

${ }^{a}$ ICA aneurysms, MCA aneurysms, and AcomA, PcomA, and posterior circulation aneurysms were compared by a mixed model approach. An overall $P$ value of $<.0038$ ( $\alpha=.05$; number of tests, 13) indicated a statistically significant difference between the 3 IA groups.

${ }^{\mathrm{b}}$ Indicates statistically significant by mixed model analysis.
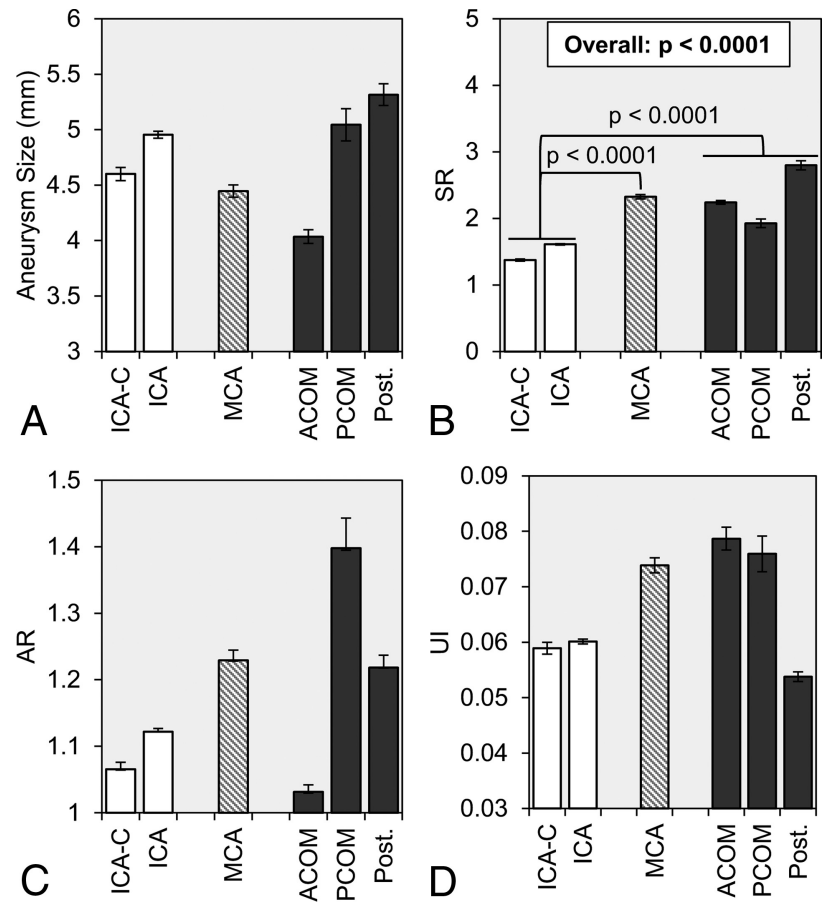

FIG 1. Statistical comparison of morphologic parameters was performed between 3 location groups: ICA (white), MCA (dashed gray lines), and AcomA, PcomA, and posterior circulation aneurysms (dark gray). The group-averaged values of $A$, aneurysm size, $B, \mathrm{SR}, C, \mathrm{AR}$, and $D, \mathrm{UI}$ are given with error bars that represent standard error. The overall $P$ value is given for SR, for which statistical significance was achieved by a mixed model comparison of the 3 groups. In addition, from pair-wise comparisons, the brackets show statistically significant differences between the ICA, MCA, and AcomA/PcomA/Post groups. AR indicates aspect ratio; ICA-C, cavernous internal carotid artery; Post, posterior circulation; UI, undulation index.

or the percentage of the aneurysm wall exposed to physiologically low WSS; maximum WSS on the aneurysm dome ${ }^{5}$; energy loss (EL), or the energy expenditure caused by viscous friction; and the pressure loss coefficient (PLc), or the pressure loss due to viscous friction. ${ }^{12}$

\section{Statistical Analysis}

To assess the differences in the morphologic and hemodynamic parameters between the 3 IA location groups, a mixed model analysis was used. This method was used to consider the potential correlation of morphologic and hemodynamic parameters between IAs from patients with multiple aneurysms and used for comparison between the 3 IA location groups. A Bonferroni correction was used, and each variable was checked for normal distribution. Non-normally distributed data were normalized by taking the square root of the data, and the outliers were identified and removed. A $P$ value of $<.004$ was considered statistically significant ( $\alpha=.05$; number of tests, 13) and indicated that a difference between the group means exists. If the variables were found to be statistically significant by the mixed model analysis, a pair-wise comparison was then performed with an $F$ test. For pair-wise comparisons, a $P$ value of $<.02$ was considered statistically significant $(\alpha=.05$; number of tests, 3). Statistical analyses were performed in SAS 9.4 (SAS Institute, Cary, North Carolina).

\section{RESULTS}

Table 2 summarizes the comparison of morphologic and hemodynamic parameters between the IA groups. Figs 1 and 2 show the mean and standard error of more discrete subsets of locations within the 3 PHASES-based location groups. As shown in Fig 1, we analyzed the difference in morphologic parameters between the 3 groups. By the mixed model analysis, we found that there was no statistical difference in the IA size between the 3 groups (overall: $P=.6236$ ). However, as shown in Fig $1 B$, SR was significantly different between the 3 groups (overall: $P<.0001$ ). Furthermore, by pair-wise comparison, we found that SR was statistically lower in ICA aneurysms $(1.54 \pm 1.17)$ compared with both MCA aneurysms $(2.35 \pm 1.25 ; P<.0001)$ and AcomA/PcomA/ Post aneurysms $(2.45 \pm 2.22 ; P<.0001)$. However, there was no difference between the group-averaged SR of MCA aneurysms and AcomA/PcomA/Post aneurysms $(P=.7387)$.

Fig 2 summarizes the comparison of hemodynamic parameters between different IA groups. By the mixed model analysis, we found that LSA and PLc were statistically different between the 3 location groups $(P=.0003$ and $P<.0001$ for LSA and PLc, respectively). As illustrated by WSS contours in Fig 3, the pair-wise comparison showed that LSA was significantly lower for ICA aneurysms $(0.097 \pm 0.182)$ compared with both MCA aneurysms $(0.206 \pm 0.271 ; P=.0084)$ and AcomA/PcomA/Post aneurysms $(0.198 \pm 0.271 ; P=.0005)$. Pair-wise comparison also showed that PLc was significantly lower in ICA aneurysms $(2.64 \pm 3.71)$ compared with both MCA $(6.06 \pm 5.23 ; P<.0001)$ and AcomA/ PcomA/Post aneurysms $(5.88 \pm 5.71 ; P<.0001)$. As illustrated by velocity streamlines in Fig 4, ICA aneurysms had more organized 

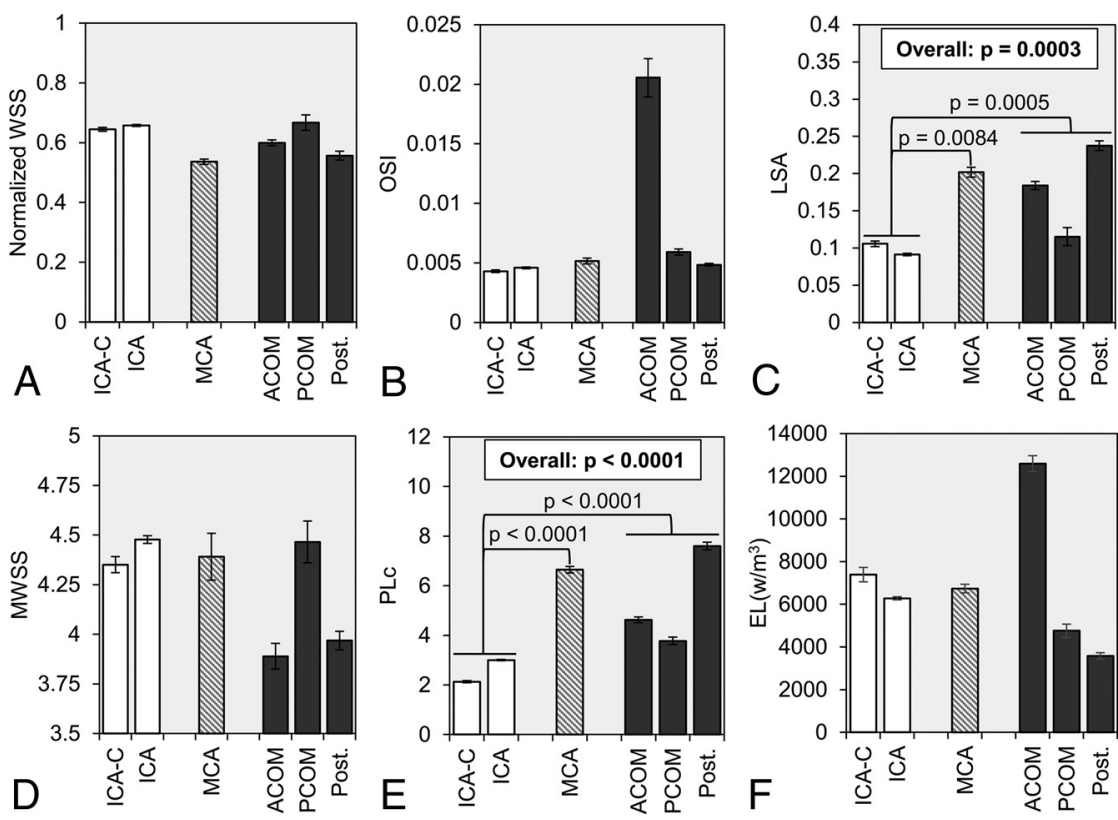

FIG 2. Statistical comparison of hemodynamic parameters was made between 3 location-based groups: ICA (white), MCA (dashed gray lines), and AcomA, PcomA, and posterior circulation aneurysms (dark gray). The group-averaged values of $A$, normalized WSS, B, OSI, C, LSA, D, MWSS, $E$, PLc, and $F$, EL are given with error bars that represent standard error. The overall $P$ value is given from LSA and PLc, for which statistical significance was achieved by a mixed model comparison of the 3 groups. In addition, from pair-wise comparisons, the brackets show statistically significant differences between the ICA, MCA, and AcomA/PcomA/Post groups. EL indicates energy loss; ICA-C, cavernous internal carotid artery; OSI, oscillatory shear index; Post., posterior circulation; MWSS, maximum normalized wall shear stress.

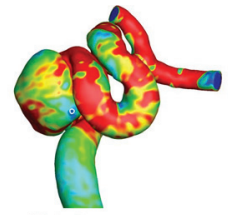

ICA Cavernous
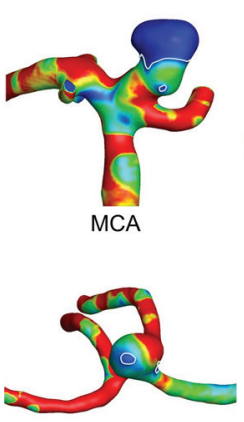

ACOM
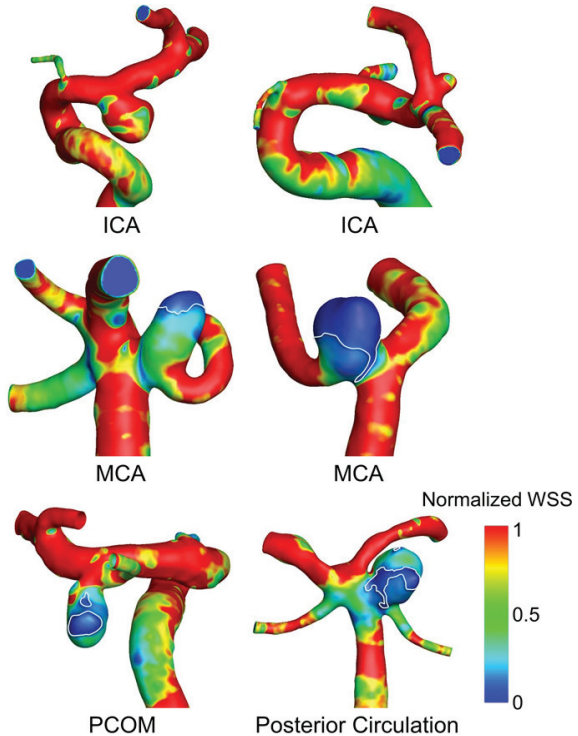

FIG 3. Normalized WSS contour plots for representative aneurysms from each of the 3 location-based groups. The areas of low WSS are outlined in white. ICA aneurysms (top), MCA aneurysms (middle), and AcomA/PcomA/Post aneurysms (bottom) are shown. ICA aneurysms had significantly higher LSA compared with both other groups.

flow patterns compared with MCA aneurysms and the aneurysms from the AcomA/PcomA/Post group. Similar to SR, for both LSA and PLc, the pair-wise comparison showed no statistical difference between MCA and AcomA/PcomA/Post aneurysms $(P=$ .8262 and $P=.4325$ for LSA and PLc, respectively).

\section{DISCUSSION}

Previous clinical studies have suggested a significant association between IA location and a higher risk of growth and rupture. ${ }^{2,4,13}$ However, there is a lack of understanding regarding the differences in aneurysm location from hemodynamic and morphologic standpoints, which might play a role in the different rupture propensities between IA locations. In this study, by using a consecutively collected aneurysm data base of 311 unruptured aneurysms from our center, we attempt to uncover morphologic and hemodynamic characteristics unique to IA locations.

Following the PHASES study by Greving et al, ${ }^{4}$ we separated the aneurysm cases in our cohort into 3 categories: ICA aneurysms, MCA aneurysms, and AcomA/PcomA/Post aneurysms, consisting of AcomA, PcomA, and posterior circulation aneurysms. We then analyzed the differences in morphologic and hemodynamic characteristics between the 3 groups by focusing on parameters found to be previously associated with rupture risk in cross-sectional datasets. $^{7,12,14,15}$ Our study finds that ICA aneurysms may have characteristics that make them the least rupture-prone.

SR, or the size of the aneurysm relative to the parent vessel, has been independently associated with rupture risk in both crosssectional ${ }^{5,10,16-19}$ and prospective studies. ${ }^{20}$ In this study, we found that SR was significantly smaller in the aneurysms from the ICA location compared with other aneurysms. Consistent with previous longitudinal studies, this suggests that these aneurysms may not be as rupture-prone as aneurysms in other locations. The finding that SR is significantly smaller in ICA aneurysms is not surprising because of the larger diameter of the parent vessel. As previously suggested, ${ }^{5}$ our data support that SR can surrogate the aneurysm location.

High SR, together with pulsatile flow conditions, may result in an adverse hemodynamic environment. Previous computational studies have found that with increasing SR, aneurysm-averaged WSS decreased and the number of vortices increased. ${ }^{21}$ In the present study, we found that MCA aneurysms and AcomA/ PcomA/Post aneurysms also had a higher LSA and PLc compared with ICA aneurysms.

Low aneurysmal WSS has been previously associated with IA rupture in location-specific studies. ${ }^{22,23}$ In 24 IAs, Chien et $\mathrm{al}^{23}$ found that low WSS was associated with IA rupture status in basilar artery and AcomA aneurysms. In addition, in 106 MCA IAs, Miura et $\mathrm{al}^{22}$ found that low aneurysm WSS was independently associated with IA rupture. WSS, the frictional force of blood on the aneurysm wall, has been shown to affect vascular remodeling and degeneration. ${ }^{24}$ WSS can be sensed by the endothelium, and persistent exposure to nonphysiologic hemodynamics has been 

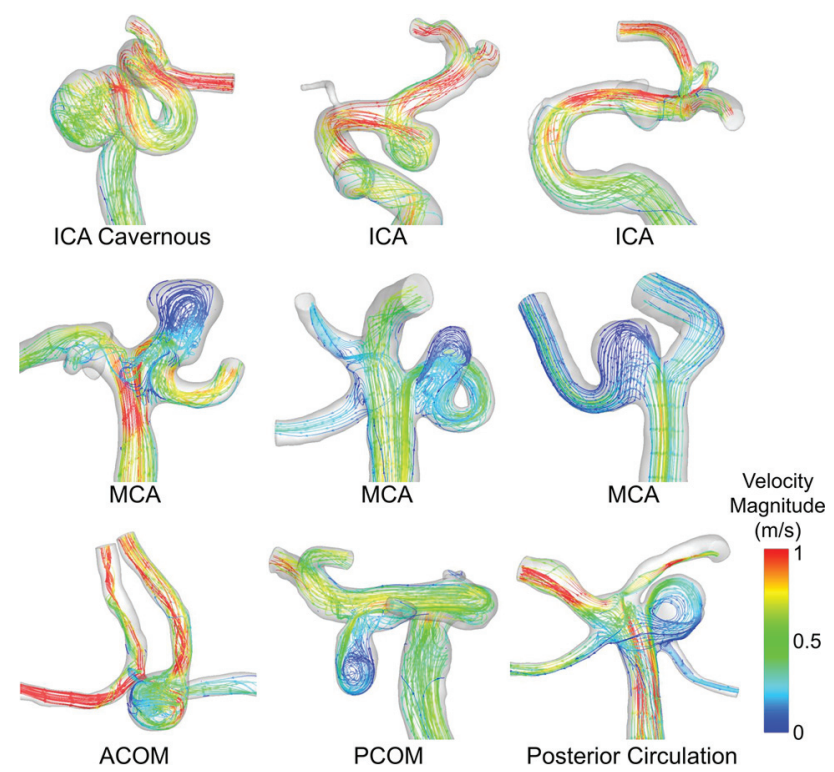

FIG 4. Velocity streamlines for representative cases from each of the 3 location-based groups. ICA aneurysms had more organized flow patterns that resulted in lower PLC.

linked to initiation, growth, and rupture of IAs. ${ }^{24-26}$ Our study suggests that aneurysms in locations other than the ICA are subjected to a low WSS hemodynamic environment that may result in higher rupture rates.

PLc is an indicator of viscous energy loss in the aneurysm because of the inflow and geometry. More complex aneurysm geometries result in complex flow patterns, higher viscous losses, and a higher PLc. Our study found that PLc was significantly different among the unruptured IAs in our cohort and was lowest in ICA aneurysms. Complex flow has been previously associated with IA rupture. A study of 117 ruptured and unruptured bifurcation IAs by Doddasomayajula et $\mathrm{al}^{27}$ showed that complex and oscillatory aneurysmal flow patterns were associated with basilar tip IA rupture, a location with high rupture rates. However, a study of 50 sidewall ICA IAs and 50 bifurcation MCA IAs by Takao et $\mathrm{al}^{12}$ showed that a lower PLc was independently associated with rupture. This difference may be because of the analysis of only unruptured IAs in our study or the presence of bifurcation and sidewall type IAs at both MCA and ICA locations in our cohort.

We also observed that the mean undulation index (irregular shape) was higher in MCA and AcomA/PcomA/Post aneurysms compared with ICA aneurysms; however, it was not statistically different between the IA location groups. The undulation index quantifies the $3 \mathrm{D}$ surface irregularities and may indicate local wall degeneration and thrombosis in the lumen potentially leading to rupture. ${ }^{28}$ Recently, the radiologic identification of aneurysm irregularities or the presence of daughter aneurysms was independently associated with aneurysm rupture in a Finnish cohort. ${ }^{29}$ Our objective quantification of surface irregularities is supported by the findings of previous work by our group that found the undulation index was a significant risk factor for rupture in our cross-sectional data base. ${ }^{5,7}$

In addition, we observed that for some morphologic and hemodynamic parameters where statistical significance was not found between IA groups, an analysis of more discrete IA locations might be warranted. The aspect ratio has been found in many large studies to be a statistically significant predictor of rupture. $^{30,31}$ Although the aspect ratio is not statistically different among the IA groups in our study, Fig $1 C$ shows that PcomA IAs have a large aspect ratio compared with other IA groups. Similarly, oscillatory shear index and energy loss have been suggested to be associated with IA rupture. ${ }^{5,32}$ As Figs $2 B$ and $2 F$ show, both the mean oscillatory shear index and energy loss are highest in the AcomA group. The complex flow in AcomA IAs is most likely caused by the 2 flow inlets that are present in AcomA aneurysms. This may lead to the collision of the inflow jets, and the directional changes of the WSS and energy losses may be amplified. Larger studies that analyze more discrete IA locations may reveal morphologic and hemodynamic differences between locations such as the AcomA and PcomA locations.

Finally, we recognize that assessing IA rupture potential is not limited to the morphologic and hemodynamic factors or the IA location. Earlier studies of ruptured and unruptured IAs that included IA location, type, and morphologic and hemodynamic parameters showed that hemodynamics did not contribute significantly to rupture discrimination. ${ }^{33}$ As suggested by the PHASES score, increased rupture propensity may be related to hypertension, patient age, and history of SAH. However, from additional analysis in our cohort, there was no statistically significant difference between patients with IAs at different locations when considering age over 70 years $(P=.5584)$, hypertension $(P=$ $.0227)$, or previous SAH $(P=.1939)$, where $P<.017$ was considered statistically significant ( $\alpha=.05$; number of tests, 3 ). Therefore, we may assume that our population is matched across IA locations when considering comorbidities relevant to the PHASES score.

Our study has several limitations. First, our data are limited to a single center, and therefore, it is unknown if our findings would apply to other datasets. Second, this study examines cross-sectional data and does not directly identify factors that can lead to future rupture at specific IA locations. Third, because of a lack of patient-specific information, we assumed that blood is non-Newtonian for computational fluid dynamics simulations, we applied a generic patient-specific waveform at the inlet, and we assumed that the vessel walls were rigid.

\section{CONCLUSIONS}

Previous studies have suggested a significant association between IA location and risk of rupture. In this study, we analyzed 311 aneurysm cases from our center and compared the differences in morphologic and hemodynamic factors. We found that SR, LSA, and PLc were different between IA groups. In addition, our results showed that ICA aneurysms had lower size ratios, less low WSS areas, and lower pressure loss coefficients compared with aneurysms in other locations. Our results suggest that ICA aneurysms have fewer rupture-prone morphologic characteristics and may be subjected to less adverse hemodynamic environments. Therefore, ICA aneurysms have better long-term outcomes with regard to rupture risk compared with other aneurysm locations.

AJNR Am J Neuroradiol 38:2105-10 Nov 2017 www.ajnr.org 
Disclosures: Nicole Varble-RELATED: Grants/Grants Pending: National Institutes of Health, Comments: R01 NS091075. Adnan Siddiqui-UNRELATED: Board Membership: Intersocietal Accreditation Committee; Consultancy: Codman \& Shurtleff, Medtronic, GuidePoint Global Consulting, Penumbra, Stryker, MicroVention, W.L. Gore \& Associates, Three Rivers Medical Center, Corindus Vascular Robotics, Amnis Therapeutics, CereVasc, Pulsar Vascular, The Stroke Project, Cerebrotech Medical Systems, Rapid Medical, Neuravi, Silk Road Medical, Rebound Therapeutics; Stock/ Stock Options: StimMed, Valor Medical, Neuro Technology Investors, Cardinal Health, Medina Medical Systems, Buffalo Technology Partners, Inc., International Medical Distribution Partners; Other: National Steering Committees: Penumbra, 3D Separator Trial, Covidien (Now Medtronic), SWIFT PRIME and SWIFT DIRECT Trials, MicroVention, FRED Trial, MicroVention, CONFIDENCE Study, LARGE Trial, POSITIVE Trial, Penumbra, COMPASS Trial, INVEST Trial. Hui Meng—RELATED: Grants/Grants Pending: National Institutes of Health-National Institute of Neurological Disorders, Comments: 5R01 NS091075*; UNRELATED: Grants/Grants Pending: National Institutes of Health Small Business Innovation Research, Comments: principal investigator Vince Tutino; Neurovascular Diagnostics*; Patents (Planned, Pending or Issued): Provisional patent on blood-based diagnostic technology, Comments: filed in 9/2016 by University at Buffalo*; Stock/Stock Options: Neurovascular Diagnostics, Comments: new small company, no monetary activities so far. Ashkan MowlaRELATED: Grants/Grants Pending: National Institutes of Health*; UNRELATED: Grants/Grants Pending: National Institutes of Health*. *Money paid to the institution.

\section{REFERENCES}

1. Vlak MH, Algra A, Brandenburg R, et al. Prevalence of unruptured intracranial aneurysms, with emphasis on sex, age, comorbidity, country, and time period: a systematic review and meta-analysis. Lancet Neurol 2011;10:626-36 CrossRef Medline

2. Wiebers DO. Unruptured intracranial aneurysms: natural history, clinical outcome, and risks of surgical and endovascular treatment. Lancet 2003;362:103-10 CrossRef Medline

3. Johnston SC, Higashida RT, Barrow DL, et al. Recommendations for the endovascular treatment of intracranial aneurysms: a statement for healthcare professionals from the Committee on Cerebrovascular Imaging of the American Heart Association Council on Cardiovascular Radiology. Stroke 2002;33:2536-44 CrossRef Medline

4. Greving JP, Wermer MJ, Brown RD Jr, et al. Development of the PHASES score for prediction of risk of rupture of intracranial aneurysms: a pooled analysis of six prospective cohort studies. Lancet Neurol 2014;13:59-66 CrossRef Medline

5. Xiang J, Natarajan SK, Tremmel M, et al. Hemodynamic-morphologic discriminants for intracranial aneurysm rupture. Stroke 2011; 42:144-52 CrossRef Medline

6. Xiang J, Yu J, Choi H, et al. Rupture Resemblance Score (RRS): toward risk stratification of unruptured intracranial aneurysms using hemodynamic-morphological discriminants. J Neurointerv Surg 2015;7:490-95 CrossRef Medline

7. Xiang J, Yu J, Snyder KV, et al. Hemodynamic-morphological discriminant models for intracranial aneurysm rupture remain stable with increasing sample size. J Neurointerv Surg 2016;8:104-10 CrossRef Medline

8. Antiga L, Piccinelli M, Botti L, et al. An image-based modeling framework for patient-specific computational hemodynamics. Med Biol Eng Comput 2008;46:1097-112 CrossRef Medline

9. Raghavan ML, Ma B, Harbaugh RE. Quantified aneurysm shape and rupture risk. J Neurosurg 2005;102:355-62 CrossRef Medline

10. Dhar S, Tremmel M, Mocco J, et al. Morphology parameters for intracranial aneurysm rupture risk assessment. Neurosurgery 2008; 63:185-96; discussion 196-97 CrossRef Medline

11. Oka S, Nakai M. Optimality principle in vascular bifurcation. Biorheology 1987;24:737-51 Medline

12. Takao H, Murayama Y, Otsuka S, et al. Hemodynamic differences between unruptured and ruptured intracranial aneurysms during observation. Stroke 2012;43:1436-39 CrossRef Medline

13. Backes D, Vergouwen MD, Tiel Groenestege AT, et al. PHASES score for prediction of intracranial aneurysm growth. Stroke 2015;46: 1221-26 CrossRef Medline

14. Meng H, Tutino VM, Xiang J, et al. High WSS or low WSS? Complex interactions of hemodynamics with intracranial aneurysm initia- tion, growth, and rupture: toward a unifying hypothesis. AJNR Am J Neuroradiol 2014;35:1254-62 CrossRef Medline

15. Xiang J, Tutino VM, Snyder KV, et al. CFD: computational fluid dynamics or confounding factor dissemination? The role of hemodynamics in intracranial aneurysm rupture risk assessment. $A J N R$ Am J Neuroradiol 2014;35:1849-57 CrossRef Medline

16. Kashiwazaki D, Kuroda S. Size ratio can highly predict rupture risk in intracranial small $(<5 \mathrm{~mm})$ aneurysms. Stroke 2013;44:2169-73 CrossRef Medline

17. Ma D, Tremmel M, Paluch RA, et al. Size ratio for clinical assessment of intracranial aneurysm rupture risk. Neurol Res 2010;32: 482-86 CrossRef Medline

18. Lin N, Ho A, Gross BA, et al. Differences in simple morphological variables in ruptured and unruptured middle cerebral artery aneurysms. J Neurosurg 2012;117:913-19 CrossRef Medline

19. Ma B, Harbaugh RE, Raghavan ML. Three-dimensional geometrical characterization of cerebral aneurysms. Ann Biomed Eng 2004;32: 264-73 Medline

20. Rahman M, Smietana J, Hauck E, et al. Size ratio correlates with intracranial aneurysm rupture status: a prospective study. Stroke 2010;41:916-20 CrossRef Medline

21. Tremmel M, Dhar S, Levy EI, et al. Influence of intracranial aneurysm-to-parent vessel size ratio on hemodynamics and implication for rupture: results from a virtual experimental study. Neurosurgery 2009;64:622-30; discussion 630-31 CrossRef Medline

22. Miura $Y$, Ishida F, Umeda $Y$, et al. Low wall shear stress is independently associated with the rupture status of middle cerebral artery aneurysms. Stroke 2013;44:519-21 CrossRef Medline

23. Chien A, Castro MA, Tateshima S, et al. Quantitative hemodynamic analysis of brain aneurysms at different locations. AJNR Am J Neuroradiol 2009;30:1507-12 CrossRef Medline

24. Meng H, Wang Z, Hoi Y, et al. Complex hemodynamics at the apex of an arterial bifurcation induces vascular remodeling resembling cerebral aneurysm initiation. Stroke 2007;38:1924-31 CrossRef Medline

25. Boussel L, Rayz V, McCulloch C, et al. Aneurysm growth occurs at region of low wall shear stress: patient-specific correlation of hemodynamics and growth in a longitudinal study. Stroke 2008;39: 2997-3002 CrossRef Medline

26. Dolan JM, Kolega J, Meng H. High wall shear stress and spatial gradients in vascular pathology: a review. Ann Biomed Eng 2013;41: 1411-27 CrossRef Medline

27. Doddasomayajula R, Chung B, Hamzei-Sichani F, et al. Differences in hemodynamics and rupture rate of aneurysms at the bifurcation of the basilar and internal carotid arteries. AJNR Am J Neuroradiol 2017;38:570-76 CrossRef Medline

28. Frösen J. Smooth muscle cells and the formation, degeneration, and rupture of saccular intracranial aneurysm wall-a review of current pathophysiological knowledge. Transl Stroke Res 2014;5:347-56 CrossRef Medline

29. Lindgren AE, Koivisto T, Björkman J, et al. Irregular shape of intracranial aneurysm indicates rupture risk irrespective of size in a population-based cohort. Stroke 2016;47:1219-26 CrossRef Medline

30. Weir B, Amidei C, Kongable G, et al. The aspect ratio (dome/neck) of ruptured and unruptured aneurysms. J Neurosurg 2003;99:447-51 CrossRef Medline

31. Backes D, Vergouwen MD, Velthuis BK, et al. Difference in aneurysm characteristics between ruptured and unruptured aneurysms in patients with multiple intracranial aneurysms. Stroke 2014;45: 1299-303 CrossRef Medline

32. Qian Y, Takao H, Umezu M, et al. Risk analysis of unruptured aneurysms using computational fluid dynamics technology: preliminary results. AJNR Am J Neuroradiol 2011;32:1948-55 CrossRef Medline

33. Schneiders JJ, Marquering HA, van Ooij P, et al. Additional value of intra-aneurysmal hemodynamics in discriminating ruptured versus unruptured intracranial aneurysms. AJNR Am J Neuroradiol 2015;36:1920-26 CrossRef Medline 